\title{
Triceps Surae Muscle
}

National Cancer Institute

\section{Source}

National Cancer Institute. Triceps Surae Muscle. NCI Thesaurus. Code C53181.

A pair of muscles in the posterior compartment of the lower leg comprising the soleus and the gastrocnemius muscles, the main function of which is plantar flexion of the foot. The soleus arises from the posterior tibia, whilst the gastrocnemius arises from the distal femur; both muscles insert into the calcaneus via the calcaneal tendon (Achilles). 